\title{
Associating findings: one important role of the radiologist
}

\author{
Associar achados: um importante papel do radiologista
}

$\overline{\text { Nelson M. G. Caserta }}{ }^{1}$

Spectacular advances in imaging diagnosis methods have significantly impacted the approach to different diseases, making the utilization of such methods almost indispensable in the follow-up as well as in the diagnosis of many such diseases. Thanks to the appropriate utilization of such imaging methods, we are able to optimize prognoses and provide safety to many procedures. Certainly, providing technological advances and updating current systems involve considerable costs which are not always easily assimilated. Because of the very characteristics of the speciality, the radiologist frequently finds himself involved in discussions and controversies brought to the general public by government entities, by medical insurance companies or by demands from society.

On many occasions the arguments are simplistic, and important decisions are made without appropriate studies, many times leading the general public to believe that the imaging diagnosis specialists are accountable for the imperfections and wrongdoings of the exaggerated utilization of diagnostic methods. In a certain way, it is just like what is going on at this very moment, with high ranking Brazilian government officials saying that, as the public health sector is doing so poorly, the solution will be to graduate more physicians or simply import them, and so maybe the people will soon forget the subject... The medical insurance companies and cooperatives act in a similar way, by cutting down on the radiologists' fees, or by refusing authorization for procedures, in order to correct their balance sheets, which they are unable to properly manage. It is very contradictory to see them disputing over prospective new customers by showing them exactly the benefits from imaging exams that we, the radiologists, place at their disposal (almost all leaflets and publicity materials show happy customers beside a modern imaging equipment!). This is the reality not only in countries like Brazil. It is a global reality. And again, the radiologists find themselves caught in discussions on cost

1. PhD, Assistant Professor, Department of Radiology, School of Medical Sciences, Unicamp State University of Campinas (FCM-Unicamp), Campinas, SP, Brazil. E-mail: ncaserta@fcm.unicamp.br. restrictions, as one can verify in articles such "What is the role of the radiologist in holding down health care cost growth?"(1).

Controlling costs and offering new procedures while maintaining the highest updated standards are only some of the continuous daily battles for most radiologists. There are many roles under radiologists' responsibilities, and many of them are not even imagined by professionals from other specialties. Offering their equipment for health insurance companies and cooperatives so that such entities can operate their business is just one of the intriguing kindnesses which are never considered when fees and cost coverage are discussed.

Back to the scientific field, there is another major role of the radiologists, which is not always noticed, albeit an essential one: collaborating with the medical team in establishing associations, detecting early findings and alerting for signs which may mean congenital anomalies or hereditary cancer syndromes. Advances in genetics have led to the discovery of connections and hereditary bases of many malignant neoplasms. It is, therefore, imperative for the radiologist to be updated on the manifestations of the most common hereditary cancer syndromes ${ }^{(2)}$. The most frequent of such syndromes are those in colorectal cancer (familial adenomatous polyposis and hereditary non-polyposis syndrome), MEN (multiple endocrine neoplasia syndrome), neurofibromatosis, Von Hippel-Lindau syndrome and Li-Fraumeni syndrome (requiring the occurrence of sarcomas in patients less than 45 years of age, in association with various other types of cancer).

Familial adenomatous polyposis (FAP) is one of the most important syndromes of hereditary colorectal cancer, with $100 \%$ penetration, which justifies prophylactic colectomy. Familial adenomatous polyposis is associated with colorectal and gastric cancer, periampullary cancer, small bowel cancer and thyroid cancer. It is also associated with desmoid tumor or aggressive fibromatosis. Its variant, Gardner's syndrome, is associated with gastrointestinal polyps, osteomas, desmoid tumor, epidermoid cysts and soft tissue tumors.

There are therefore great numbers of associations which the radiologist must know, some of them requiring preventive imag- 
ing and early detection, which can help in reducing morbidity and mortality of patients ${ }^{(2)}$.

Sometimes, the knowledge on some symptoms or manifestations may prompt the radiologist to investigate some findings or alterations. In the current issue of Radiologia Brasileira, the article approaching congenital anomalies of the inferior vena cava shows an example of this important role of the radiologist ${ }^{(3)}$. Such anomalies are uncommon; however, some of them have very important clinical and surgical implications. One of such situations is that of the young patient with lower limb thrombosis. Anomaly of the inferior vena cava represents a possible risk factor affecting the venous return, with stasis in lower limbs and development of varices. Certainly there are other etiological factors, such as hypercoagulability related to hematologic and neoplastic abnormalities, trauma and other causes of increased extraluminal pressure, but all of them require knowledge from the radiologist and attention to investigate possible associations interfering with the clinical condition of the patient.

Those are, therefore, examples of the various relevant roles of the radiologist in the medical practice, and the importance of such professionals in establishing the relationship between imaging findings and their impact on the patients' prognosis.

\section{REFERENCES}

1. Forman HP, Beauchamp NJ Jr, Kaye A, et al. What is the role of the radiologist in holding down health care cost growth? AIR Am J Roentgenol. 2011;197:91922.

2. Shinagare AB, Giardino AA, Jagannathan JP, et al. Hereditary cancer syndromes: a radiologist's perspective. AJR Am J Roentgenol. 2011;197:W1001-7.

3. Yang C, Trad HS, Mendonça SM, et al. Anomalias congênitas da veia cava inferior: revisão dos achados na tomografia computadorizada multidetectores e ressonância magnética. Radiol Bras. 2013;46:227-33. 